\title{
EVALUATION OF THE ENVRIONMENTAL FEATURES OF VERNACULAR ARCHITECTURE. A CASE STUDY IN CYPRUS
}

\author{
M. Philokyprou*, A. Michael \\ University of Cyprus, Department of Architecture, Nicosia, Cyprus P.O Box 20537 Nicosia 1678, \\ mphiloky@ucy.ac.cy, aimilios@ucy.ac.cy
}

KEY WORDS: sustainability, thermal comfort, vernacular, bioclimatic

\begin{abstract}
:
Traditional settlements are by definition sustainable in relation to their environmental context and available resources. This paper investigates the environmental behaviour of vernacular architecture and the identification of the different factors that contribute to a pleasant environment and thermal comfort within traditional buildings and their surroundings. This investigation is part of an extended ongoing research programme which is the first research programme regarding the vernacular architecture of Cyprus that includes in situ measurements of temperature, humidity and ventilation using data loggers and weather stations. The results indicate the bioclimatic design elements of Cyprus' vernacular architecture and more specifically the passive strategies for heating (solar gains, thermal mass, thermal inertia), cooling (sun-shading, ventilation) and optimization of environmental microclimatic conditions (planting, evaporation). The analysis shows a relatively stable indoor temperature regardless of the fluctuation of outdoor temperature due to the considerable thermal mass of the structure. The data also indicates that the internal temperature reaches a maximum value later in the day compared with the external environment. This is related to the thermal inertia of the building's envelope that delays the heat transfer from the external environment to the internal space. Through this research the great significance of the internal courtyard was underlined, which serves as a microclimate regulator, keeping the temperature at higher levels than the external environment during the winter period. Taking into consideration the sustainability of vernacular architecture, the essential skills for environmentally-friendly approaches to the built environment can be developed, which will benefit society as a whole.
\end{abstract}

\section{INTRODUCTION}

Sustainable development is a priority for the building activities of many countries as these activities constitute an important part of energy consumption. In this framework the study of vernacular architecture can offer effective solutions towards the built environment being by definition sustainable in relation to its environmental context, using locally available resources to address local needs. Traditional settlements are well adapted to their surroundings (natural and social), respond to humans' actual needs, incorporate many features friendly to the environment (structure, forms, layout), and are thus considered as a model for sustainable design [1] and as a contribution to new methods and solutions for the future built environment [2]. As Rapoport [3,4] stresses, the form of a traditional house is defined by a series of socio-cultural factors and is shaped by climatic conditions, the available materials and the construction techniques. In addition, the rehabilitation of vernacular buildings constitutes by itself an important sustainable attitude towards the existing built environment as this incorporates the conservation of non-renewable sources.

Cyprus offers an excellent case for the study and analysis of the environmental features of vernacular architecture as it is a small island which incorporates many different types of dwellings and numerous features situated in different environments and climatic conditions. It has mountainous as well as plain and coastal areas with a variety in forms of dwellings in relation to date, layout, materials and construction methods. The typology often changes within a short distance in relation to the immediate environment depending also on the availability of materials $[5,6]$.

In this paper we present the first analytical study to-date of environmental measurements of vernacular dwellings of Cyprus. The results of this study are part of an extended ongoing programme, the main objective of which is the overall investigation of environmental features of vernacular dwellings all over the island. Similar studies were carried out for the investigation of vernacular architecture of other countries of the Mediterranean Sea [7,8] and in other areas [9] but not in Cyprus.

\subsection{The aims of the paper and the research}

This research study aims to investigate the bioclimatic strategies followed in traditional dwellings and at the same time to assess the significance of conserving vernacular architecture. For this purpose in situ measurements and qualitative analysis of the behaviour of a characteristic traditional building in a rural semimountainous village of Cyprus in different seasons and weathering conditions were carried out - as a pilot case study. This will be followed by measurements in more vernacular structures in the same village and also in vernacular dwellings of other traditional settlements with a different geomorphology (mountainous areas, plains and cities).

The overall objective of this research is to produce new scientific knowledge, which will contribute to the sustainable development of the existing environment, "encouraging the sustainable use of resources and strengthening synergies between environmental protection and development" (National Reform Program for Lisbon).

This research aims at exploring and identifying the bioclimatic design principles and elements which have been applied, over time, in traditional architecture, in order to establish new ways of restoring traditional buildings, by focusing on maintaining and improving the above-mentioned principles. This research attempts to draft a set of guidelines and proposals for the proper conservation and restoration of traditional buildings, with 
emphasis on maintaining and enhancing the bioclimatic characteristics and environmentally-friendly approaches, through innovative solutions.

\subsection{Analysis of bioclimatic elements of the vernacular architecture}

Bioclimatic design refers to the incorporation of nature elements in architecture design, aiming at the improvement of comfort conditions - thermal, visual, acoustic comfort, indoor air quality - of the inhabitants of traditional buildings and the minimization of energy consumption. It is related to the application of a series of strategies in design and construction, which refer to passive heating and cooling, as well as to the improvement of microclimatic conditions of the surrounding environment and the exploitation of natural lighting.

The investigation of the different bioclimatic elements of vernacular architecture covers the exploration of the following features:

- Central courtyard (arrangement of closed and semi-open spaces around a central yard).

- Semi-open spaces / iliakoi (comfortable intermediate living spaces).

- Plants and water features in the courtyards (evaporating, cooling).

- Orientation of the house (arrangement of large openings towards the south for solar gains and small openings towards the north for minimizing thermal losses during winter).

- Traditional strategies for shading (roof overhangs, pergolas, plants, solid plank or adjustable shutters) and arrangement of semi-open spaces (iliakoi, porches, galleries) in front of the south side of the buildings $[10,11]$.

- Traditional strategies for ventilation (multiple openings for cross ventilation, stack effect) and night cooling.

- Construction materials and quality of the building envelope (materials with thermal inertia such as mudbricks, stone walls and materials with thermal insulation properties such as successive layers of clay, twigs and straw for roofs).

- Relationship of buildings to their immediate built and natural environment (location in the urban core / nucleus, proximity to other buildings).

\section{CASE STUDY}

A systematic research was initiated to investigate the bioclimatic elements of the vernacular architecture of Cyprus and is concentrated on the semi-mountainous traditional settlement of Kapedes where specific measurements of temperature, relative humidity and air velocity were recorded. In Kapedes, like most of the vernacular settlements of the island, locally available materials are used which reduce the energy consumption and the environmental impact, reinforcing at the same time the local characteristics of the settlement. The traditional rural architecture of the village is characterized by passive control elements such as stone walls with high thermal inertia and small windows representing the main elements of architectural expression. The traditional buildings are successfully integrated into their immediate environment being frequently arranged in compact patterns, closely built with common walls, one next to the other, leaving small empty spaces in the form of alleys and courtyards (Figure 1). Thus, the vertical surfaces (walls) exposed to solar radiation are reduced and the thermal inertia of the ensemble is raised. The shade between neighbouring buildings reduces the warming up of their walls by radiation and at the same time enables them to be cooled by contact with the cool air at night. Thus, nature, climate and topography are important parameters that play a significant role in the design. Streets are very narrow, surrounded by one or two-storey dwellings that offer shading to the passage way.

In order to have a more accurate qualitative and also quantitative assessment, a specific house that incorporates most of the above mentioned climatic characteristics was selected for investigation. The house consists of an iliakos, serving as an entrance and also as an intermediate space between the street and the house (Figures 2-4), a large double room (dichoro), a kitchen and some other small auxiliary rooms on the ground level and two bedrooms on the second level.



Figure 1. Aerial view of a part of the settlement

The load bearing structure of the house is built of internallyplastered masonry consisting of local stone and mudbricks. These walls are $50 \mathrm{~cm}$ thick at the ground level and about 40 $45 \mathrm{~cm}$ thick on the first floor level. The roof is made of timber, reeds and clay and is covered by tiles. The house has been conserved recently in its original form, preserving almost all its authentic characteristics. More specifically, the shell of the house has been conserved and only the roofs were repaired using insulation in the place of the original layers of earth and clay. All the openings were conserved and the original planks were replaced (Figure 4). A glass door was installed in the original arch opening of the iliakos so as to achieve internal circulation between the different rooms (Figures 5-6).

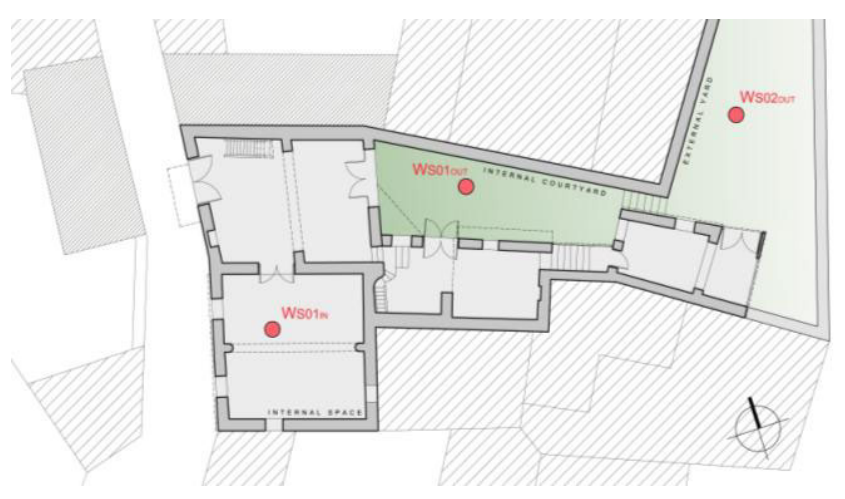

Figure 2. Plan of the house showing the measuring points (internal space, courtyard and external environment) 


\section{A CASE STUDY IN CYPRUS}
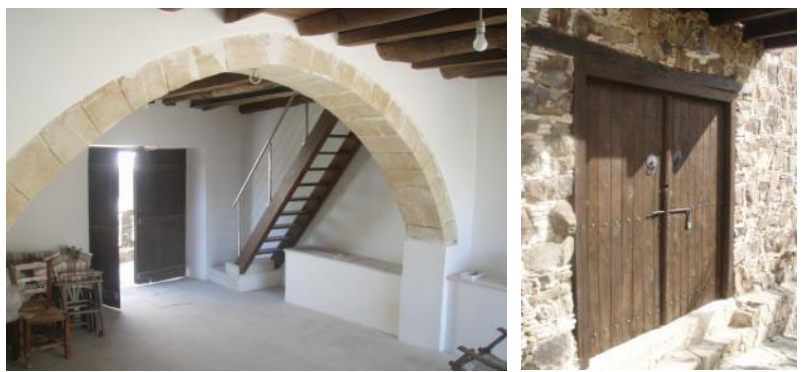

Figures 3-4. Internal view of the iliakos (Figure 3). The main entrance of the house (Figure 4).

\subsection{Qualitative and quantitative evaluation of the house}

The various rooms of the dwelling are arranged around a rather small central yard which constitutes a bioclimatic element of utmost importance (Figures 5-6). The small size of the courtyard operates as a microclimate regulator in the residence, assisting the integration of nature elements into the design and overall architectural concept of the building. The courtyard proportions and the arrangement of the rooms around it, especially the two-storey parts of the house, block the winds during winter and thus mitigate low temperatures. The small size of the courtyard is an excellent thermal regulator because its size helps towards the shading of the largest part of the walls during the day, allowing less thermal impact and more heat dissipation from adjoining indoor spaces. The whitish slabs of the courtyard as well as the surrounding walls act as a good radiator of heat and light penetration. Moreover, the courtyard ensures a pleasant view and visual comfort which contribute to the emotional and psychological condition of the occupants. According to Sullivan [12], "The courtyard integrates a wide variety of passive devices into its design, each creating its own thermal environment."
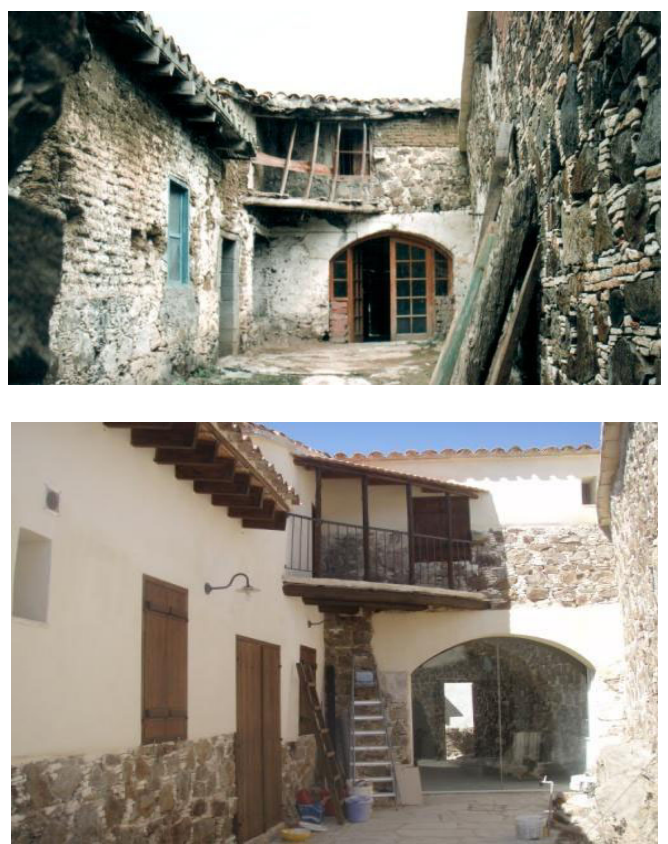

Figures 5-6. View of the house through the central courtyard before and after conservation.
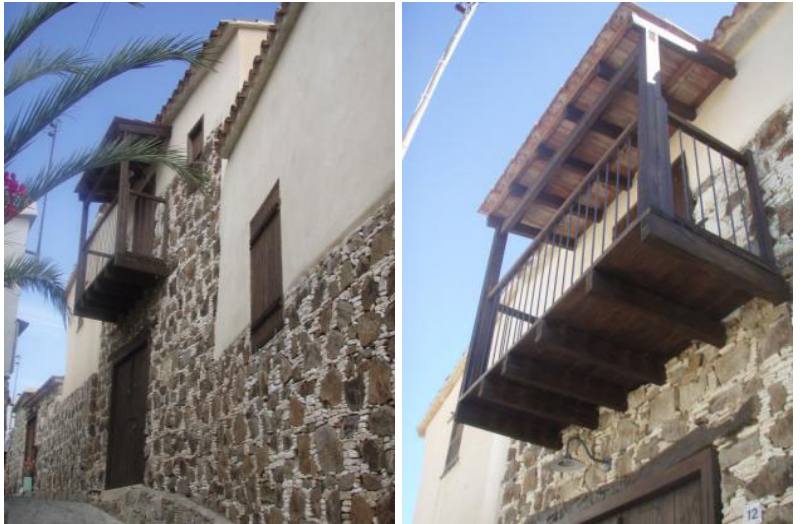

Figures 7-8. West elevation of the house after conservation (Figure 7). The balcony above the main entrance of the house (Figure 8)

The iliakos, a semi-open space, in close relation with the yard, serves as an intermediate space between closed and open spaces and also as a buffer zone between the street and the courtyard, channelling breezes and improving the ventilation of the house. In the traditional residence under study, sun protection is achieved through the use of appropriate sun shading elements on the openings. The traditional envelope incorporates a linear cantilever (balcony) on the front of the west openings (Figure 78 ). The thicknesses of the walls also ensure some shading of the openings. Moreover, the solid plank shutters of the openings provide shade and reduce the direct solar radiation (Figure 4). Several of the building's openings and part of the courtyard are sufficiently shaded from the surrounding built environment and the building itself (Figure 9). In addition, the sun protection elements contribute to the normalization and filtration of the natural lighting, which enters the interior space.

Ventilation is mainly achieved through the various openings of the house and especially through their cross arrangement (Figure 10). They are designed in size and placed proportionally in order to allow the required amount of light and air circulation and to provide comfort. Windows facing the exterior are minimized so as to be consistent with interior requirements. Small openings (arseres), specially placed on a high level, enable the hot air to escape to the outdoor environment during the cooling period and at the same time provide daylight to the maximum depth possible with minimum penetration of radiation and serve ventilation needs when the house is not occupied. The removal of hot air is also achieved through the staircase opening situated in the iliakos of the house (Figure 3). Most of the openings of the dwelling (seven) are arranged around the central yard underlying the importance of the yard with regard to the ventilation and cooling of individual rooms. Thus, the courtyard provides a unique opportunity of orientation of the house in relation to sunlight and ventilation and modifies the amount of sunlight entering the house, improving the microclimate.

Direct solar gains are the main strategy of bioclimatic design during the winter period. East, west and south-facing elevations benefit from the incoming solar energy through both the building envelope and the appropriate openings. The direct solar gains of the house seem to be rather limited due to the general layout of the house which was derived from the size and shape of the plot and the surrounding buildings. 

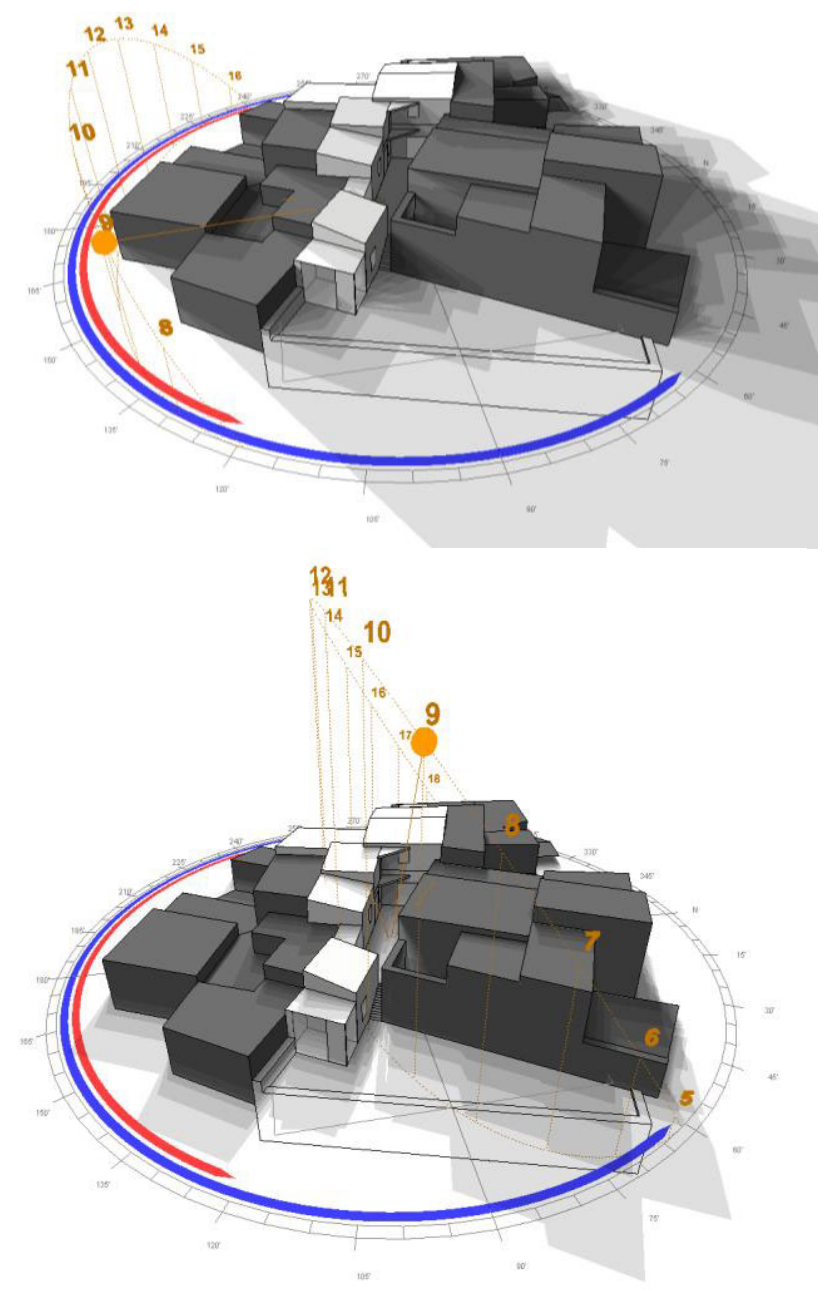

Figure 9. Simulation of shading range for winter and summer solstice (Ecotect software v.5.2).

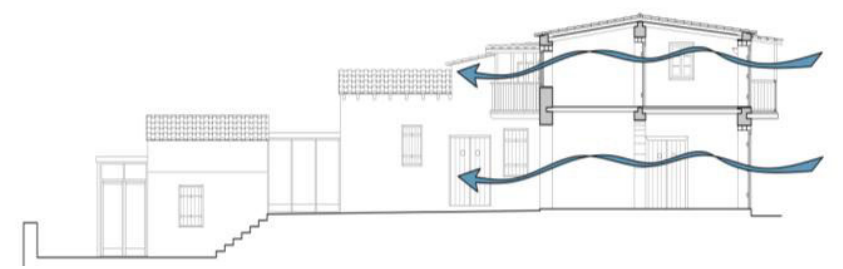

Figure 10. Traditional strategies for ventilation (cross ventilation and night cooling).

The application of proper materials (local stone, earth in the form of mudbricks, etc) and construction techniques (structure of roofs) ensure adequate thermal insulation and thermal inertia of the building envelope. The use of solid plank shutters in the openings prohibits the hot and cold air entering the house in summer and winter respectively.

The penetration of natural lighting is ensured through multiple openings in the building envelope. The distribution of natural lighting is also influenced by the configuration of the interior and the reflections of the surrounding surfaces within the building. Openings towards the courtyard provide visual connections as well as the possibility of physical connections with the external environment and nature.

Beyond the bioclimatic principals, the environmental approach of the traditional envelope refers to the selection of appropriate building materials to minimize the ecological footprint of the building. The reduction of the environmental damage, apart from the use of appropriate building materials (raw natural and local materials with low $\mathrm{CO}_{2}$ emission and low embodied energy) refers to the use of appropriate building techniques (dry and assembled construction) and methods that allow re-use of the major part of construction materials of the building (recycled without downgrading the quality of materials).

\subsection{Methodology}

The quantitative analysis of this specific traditional residential building comprises the investigation and documentation of the applied design strategies for the improvement of microclimatic conditions. For the data acquisition, DAVIS Vantage Vue weather stations were placed for a period of six months in selected places of the residence under study (Figure 2). The measurements were conducted every 5 minutes from the 20th of December, 2011 until the 10th of June, 2012.

The registration equipment was placed in three selected places: (a) in the external yard for the registration of the external environment climatic data, (b) in the residence's central courtyard for the registration of the climatic data in the courtyard, and (c) in the most important internal space of the ground floor (dichoro), all measured at a height of $100 \mathrm{~cm}$ above the finished floor. The measurements of temperature and relative humidity refer both to the winter and the summer period. During both periods under study the residence was unoccupied having all of the openings closed, thus constantly eliminating all the internal heat gains.

\subsubsection{Thermal Performance Analysis for the Winter Period:} The measurements of temperature and relative humidity for the time span of one week were analysed for the winter period $\left(19^{\text {th }}\right.$ of February 2012, 00:00 hrs $-25^{\text {th }}$ of February 2012, 24:00 hrs). The internal space has no technical support for heating. The measurements of temperature and relative humidity are presented in the graphs below (Figures 11, 12, 13).

The maximum temperature of the building's internal space for the winter period $\left(19^{\text {th }}\right.$ of February $2012,00: 00 \mathrm{hrs}-25^{\text {th }}$ of February $2012,24: 00 \mathrm{hrs}$ ) is $11.3^{\circ} \mathrm{C}$, i.e. $2.6^{\circ} \mathrm{C}$ lower than the maximum temperature of the external environment. The respective temperature value of the climatic data in the courtyard during the same time period is $17.7^{\circ} \mathrm{C}$, i.e. $3.8^{\circ} \mathrm{C}$ higher than the maximum temperature of the external environment. The minimum temperature of the building's internal space is $8.6{ }^{\circ} \mathrm{C}$, i.e. $8.0^{\circ} \mathrm{C}$ higher than the minimum temperature of the external environment.

The respective temperature value of the climatic data in the courtyard during the same time period is $1.7^{\circ} \mathrm{C}$, i.e. $1.1{ }^{\circ} \mathrm{C}$ higher than the minimum temperature of the external environment. The temperature fluctuation for the building's internal space is $2.7{ }^{\circ} \mathrm{C}, 16.0^{\circ} \mathrm{C}$ for the courtyard and $13.3^{\circ} \mathrm{C}$ for the external environment. During the same time period, the mean temperature for the building's internal space is $10.2{ }^{\circ} \mathrm{C}$, i.e. $1.8{ }^{\circ} \mathrm{C}$ higher than the mean temperature of the external environment and $2.9^{\circ} \mathrm{C}$ higher than the mean temperature of the climatic data in the courtyard (Figure 14). The comparison bars of relative humidity during the winter period are shown in the diagram below (Figure 15). 


\section{A CASE STUDY IN CYPRUS}

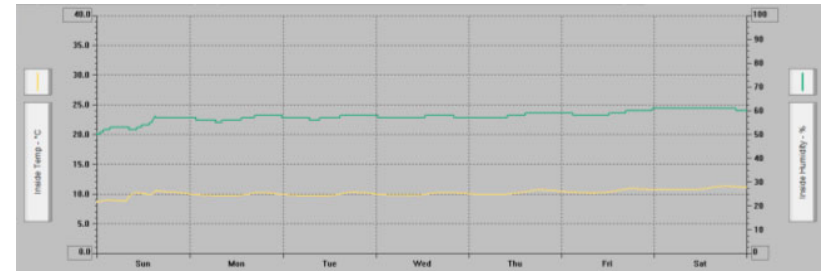

Figure 11. Temperature and Relative Humidity data of the building's internal space (dichoro) for the winter period $\left(19^{\text {th }}-\right.$ $25^{\text {th }}$ February, 2012).

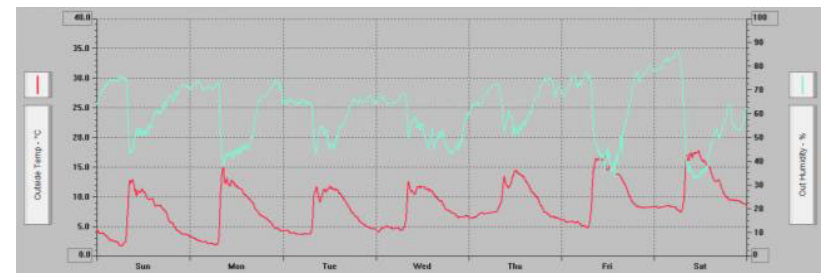

Figure 12. Temperature and Relative Humidity data of the courtyard for the winter period $\left(19^{\text {th }}-25^{\text {th }}\right.$ February, 2012).



Figure 13. Temperature and Relative Humidity data of the external environment for the winter period $\left(19^{\text {th }}-25^{\text {th }}\right.$ February, 2012).


Figures 14- 15. Comparison bars of temperature and relative humidity during the winter period (19th -25 th February, 2012).
2.1.2. Thermal Performance Analysis for the Summer Period:The measurements of temperature and relative humidity for the time span of one week were analysed for the summer period ( $3^{\text {rd }}$ of June $2012,00: 00 \mathrm{hrs}-9^{\text {th }}$ of June 2012, 24:00 hrs). The internal space has no technical support for cooling. The measurements of temperature and relative humidity are presented in the graphs that follow (Figures 16, 17, 18).

The maximum temperature of the building's internal space for the summer period $\left(3^{\text {rd }}\right.$ of June 2012, 00:00 hrs $-9^{\text {th }}$ of June $2012,24: 00 \mathrm{hrs}$ ) is $25.0^{\circ} \mathrm{C}$, i.e. $6.9^{\circ} \mathrm{C}$ lower than the maximum temperature of the external environment. The respective temperature value of the climatic data in the courtyard during the same time period is $36.3{ }^{\circ} \mathrm{C}$, i.e. $4,4{ }^{\circ} \mathrm{C}$ higher than the maximum temperature of the external environment. The minimum temperature of the building's internal space is 22.0 ${ }^{\circ} \mathrm{C}$, i.e. $5.7{ }^{\circ} \mathrm{C}$ higher than the minimum temperature of the external environment. The respective temperature value of the climatic data in the courtyard during the same time period is $18.0^{\circ} \mathrm{C}$, i.e. $1.7^{\circ} \mathrm{C}$ higher than the minimum temperature of the external environment.

The temperature fluctuation for the building's internal space is $3.0^{\circ} \mathrm{C}, 18.3{ }^{\circ} \mathrm{C}$ for the courtyard and $15.6{ }^{\circ} \mathrm{C}$ for the external environment. The mean temperature for the building's internal space, the external environment and the climatic data in the courtyard ranged at approximately the same levels, $23.5{ }^{\circ} \mathrm{C}$, $25.2{ }^{\circ} \mathrm{C}$ and $23.3{ }^{\circ} \mathrm{C}$ respectively (Figure 19). The comparison bars of relative humidity during the summer period are shown below (Figure 20).

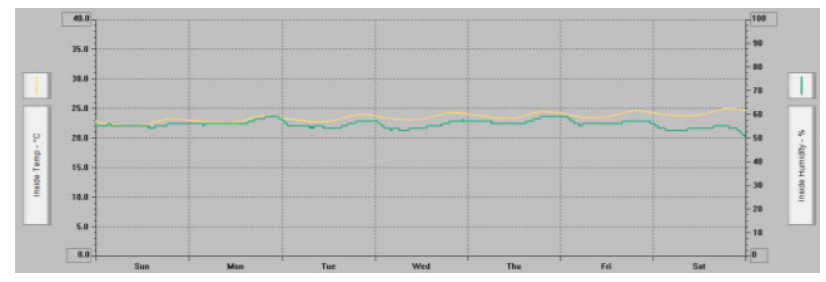

Figure 16. Temperature and Relative Humidity data of the building's internal space for the summer period $\left(3^{\text {rd }}-9^{\text {th }}\right.$ June, 2012).

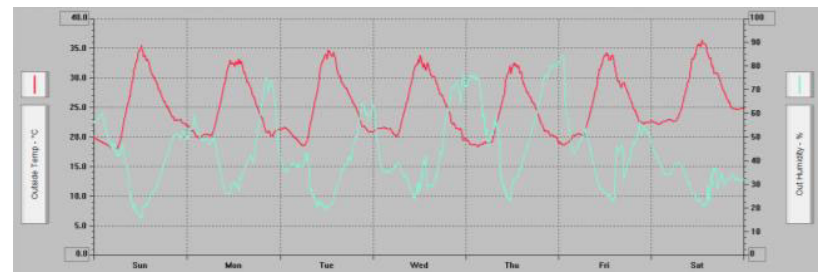

Figure 17. Temperature and Relative Humidity data of the central courtyard of the house for the summer period $\left(3^{\text {rd }}-9^{\text {th }}\right.$ June, 2012).

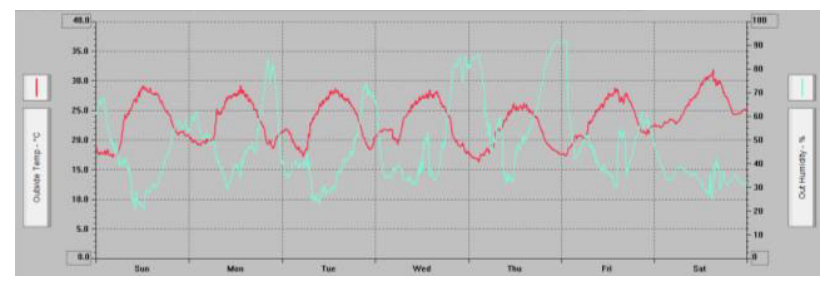

Figure 18. Temperature and Relative Humidity data of the external environment for the summer period $\left(3^{\text {rd }}-9^{\text {th }}\right.$ June, 2012). 



Figures 19- 20. Comparison bars of temperature and relative humidity during the summer period (3rd - 9th June, 2012).

\section{CONCLUSIONS}

The thermal performance analysis of the temperature and relative humidity for the above-mentioned periods provides for the first time in a scientific way, information on the thermal behaviour of a vernacular house in Cyprus. The analysis shows that the indoor temperature was relatively stable regardless of the fluctuation of outdoor temperature due to the considerable thermal mass of the structure. During the summer period, the indoor environment provides thermal comfort, although during the winter period the house's envelope fails to adequately retain heat at a comfortable level. The data shows that the internal temperature reaches a maximum value later in the day compared with the external environment. This is related to the fact that the thermal inertia of the building's envelope delays the heat transfer from the external environment to the internal space.

Through the study and in situ measurements of the temperature and humidity in a vernacular dwelling, the great significance of the internal courtyard was underlined, which serves as a microclimate regulator, keeping the temperature at higher levels than the external environment during the winter period. Although the courtyard is sufficiently shaded from the surrounding built environment, during the summer period an increase of the temperature in comparison to the external environment is recorded. This is due to the lack of proper planting in the courtyard as well as due to the closing of the iliakos's opening with a glass door prohibiting the cross ventilation of the house.

Thermal comfort in a traditional dwelling largely depends on the way the occupants make use of the house. The fact that the house under study was unoccupied during most of the period under investigation did not permit the application of solar gain strategies in the winter period and did not permit the application of cross ventilation and stack-effect strategies during the summer period.
Vernacular dwellings in Cyprus have adapted relatively well to climatic conditions by using low-energy design principles that ensure human comfort. The solutions followed were simple and easy to apply but at the same time they proved to be very efficient, showing a deep understanding of the adaptation to the surrounding environment. A systematic knowledge of traditional architecture and building technologies is the basis for supporting stable, balanced and sustainable socio-economic development and promoting conservation and rehabilitation of vernacular architecture. A deep and meaningful engagement with vernacular architecture and the rehabilitation process can inspire creative designs that sustain the productive life of the existing environment.

\section{REFERENCES}

1. Heal, A., Paradise, C. and Forster, W.: The Vernacular as a Model for Sustainable Design, Proc. 23th Conference on Passive and Low Energy Architecture, Geneva (2006).

2. Asquith, L. and Vellinga, M.: Introduction, Vernacular Architecture in the Twenty-First Century: Theory Education and Practice (2006).

3. Rapport, A.: Vernacular Design as a Model System in Vernacular Architecture in the $21^{\text {st }}$ Century: Theory Education and Practice, ed. by L. Asquith and M. Vellinga (2006).

4. Rapoport, A.: The nature of Courtyard House: A conceptual Analysis, Traditional Dwellings and Settlements Review, Vol. XVIII, Number II, pp. 57-72 (2007).

5. Sinos, S.: A Review of the Vernacular Architecture of Cyprus. Athens (1976).

6. Ionas, J.: La Maisone Rurale de Chypre. (XVII-XXe siècle). Aspects et Techniques de Consturction, Nicosia Publications of the Science Research Centre. Nicosia. Cyprus (1988).

7. Vissilia, A.M.: Evaluation of a Sustainable Greek Vernacular Settlement and its Landscape Architecture. Building and Environment 44, 1095-106 (2009).

8. Canas, I. and Martin, S.: Recovery of Spanish Vernacular Construction as a Model of Bioclimatic Architecture. Building and Environment 39, 1477-95 (2004).

9. Anh-Tuan, N., Quoc-Bao T., Duc-Quang T. nad Sigrid, R.: An Investigation on Climate Responsive Design Strategies of Vernacular Housing in Vietnam. Building and Environment 46, 2088-2106 (2011).

10. Papacharalambous, G.: The Cypriot Dwelling. Cyprus Research Center II. Nicosia (1968).

11. Sinos, S.: Types of Rural Dwellings in Cyprus", in Acts of the International Archaeological Symposium "Cyprus Between the Orient and the Occident", Nicosia, September (1985).

12. Sullivan C.: Garden and Climate. New York: McGraw-Hill (2002).

\section{AWKNOWLEDGE}

The authors would like to awknowledge funding from the University of Cyprus (research programme - Starting Fund of Maria Philokyprou). This is the first research programme carried out in Cyprus which includes in situ measurements of temperature and humidity in vernacular dwellings all around the island. The aim of this research programme is to gather architectural, environmental and historical data from various traditional settlements (mountainous, semi-mountainous, plains) and create a digital data base connected with a web site. 